\title{
Using interactive technologies to improve the quality of humanitarian education in a metropolis
}

\author{
Olga Shakirova $^{1 *}$, Tatyana Stebliy ${ }^{1}$, Nina Kozyavina $^{1}$, Olga Gorbunova ${ }^{1}$, and \\ Olga Pavlovskaya ${ }^{1}$ \\ ${ }^{1}$ Far Eastern Federal University, Vladivostok, Russia
}

\begin{abstract}
Modern society presents high requirements to the quality of humanitarian education, and one of the methods of optimization is the use of interactive education technologies. Formation of the system of teacher's domination in implementation of active learning methods (ALM) is based on the development of meaningful components of own subject experience, representing continuous and purposeful process, the active use of which is an expression of independence and educational activity. In the metropolis environment, the degree of development of each component of the subject experience and their ratio between each other determine the teacher's ability to construction and subsequent implementation of own educational route. The research objective was to develop a model of ALM selection for humanitarian education in metropolis and estimate it experimentally with consideration for existing level of development of subject experience of teachers of higher education. The research was based on theoretical (analysis of psychological and pedagogical scientific publications, regulatory documents, state educational standards, simulation, analysis and generalization of pedagogical experience) and practical (monitoring, expert appraisal, pedagogic experiment) methods. For the first time, the objective and subjective factors have been revealed and systemized, which can influence the development and subsequent implementation of subject experience of teachers in humanitarian education under conditions of metropolis. With consideration for highlighted scientifically substantiated meaningful components of subject experience, the model has been developed to support ALM by teachers depending on the level of formation of subject position of a teacher. During the performed pedagogical experiment the efficiency of different variants of the recommended model of pedagogical support during ALM selection has been determined.
\end{abstract}

Keywords: humanitarian education, active learning methods, teacher of higher education.

\section{Introduction}

Searching for methods of pedagogical support, required for a teacher for reasonable selection of ALM in the course of humanitarian education in metropolis on the basis of own subject experience, is the main topic of this research. Construction of own presentation about the

\footnotetext{
* Corresponding author: shakirova.ov@dvfu.ru
} 
teacher's subject experience, highlighting its main components: motivation and value, reflective and evaluation, creative and activity, became possible on the basis of analysis of scientific and methodological publications and generalization of existing pedagogical experience in the area of urban humanitarian education [1-3].

\section{Methods}

The experimental base for the research was School of Arts and Humanities (SAH), Far Eastern Federal University. Agreement for participation in the research was obtained from 42 teachers, seven of them $(16.6 \%)$ had the degree of candidate of sciences. Average age of the academic staff was $51.8 \pm 1.6$ years, of academic experience $-25.9 \pm 0.7$ years. In order to determine specificity and level of formation of the existing professional subject experience, each teacher was tested and surveyed [4-6].

\section{Results}

According to the test results, the teachers were subdivided into three subgroups depending on the level of own professional subject experience. The first group was comprised of 11 teachers $(26.1 \%)$ with the low level of professional subject experience, who did not consider their subjectivity as a source of own activity, herewith, disclaiming existence of any professional problems. Their social creativity and internal confrontation were at the low level, activity and responsibility for formulation and solution to professional tasks were nearly absent, which allowed to shift the blame for their mischiefs to other shoulders. In the second group, comprised of the majority of participants: 28 persons $(66.6 \%)$, the formation of professional subject experience was at the medium level, characterized by the low level of social creativity and expressed ability of independent target setting. For such teachers, selfactualization was not the main demand, which could lead to difficulties upon occurrence of abnormal situations, though, the self-improvement was always related with career growth. High level of professional subject experience, characterized by high responsibility and social creativity, ability to efficiently plan their actions and critically evaluate the obtained results, was detected only in three teachers (7.1\%), who comprised the third subgroup, and for whom the main source of activity was not a directed external action but their own subjectivity. The academic staff was characterized by somewhat simplified understanding of mechanism of system and activity approach upon implementation of ALM into education. Therefore, upon development of model of pedagogical support, the main attention was paid to the need to explain to teachers the novelty of methodological principles and planning tools, to the achievement and evaluation of subject, meta-subject, and personal results with the focus on personal qualities of teacher. It was revealed that it would be reasonable to select protection as strategy, if fear prevented active actions by the teacher; the tactics of assistance should be implemented, if the teacher was not sure in own capacities. It was necessary to initiate selfanalysis through assistance, if the teacher intentionally excluded analysis for selection of optimum variants due to obvious own overestimation. When the teacher, despite adequate understanding the problem, was characterized by obvious lack of capacities for its solution, it was necessary to interact during mastering material.

\section{Discussion}

The choice and use of ALM in teacher's professional activity in educational environment of metropolis should be carried out consecutively and gradually in several stages. At the first stage, it is required to provoke interest of teachers in new forms of work, to attract with 
information about efficient activity, to demonstrate the necessity of ALM in professional activity. It would be reasonable to invite teachers as experts to classes with ALM, prepared by their colleagues. This would allow to actively involve the teachers in the work with ALM, and useful addition to the classes will be reflective conversation resulted in the table summarizing advantages and disadvantages of the used ALM. At the next stage, it is assumed that teachers would further comprehend the advantages of education using ALM; psychological assistance of the head of department, director of academic department or head of chair is highly required. The psychological assistance can be presented in the form of reflective conversation upon individual consultations, during which on the basis of existing motivation and urgent needs of the teacher, it is required to carefully determine the personal properties, which will allow to perform correct choice of ALM based on own subject experience of the teacher. After completion of classes, the reflective conversations allow to estimate, how fully and how correctly were performed the planned actions. At the third stage, it is recommended to fill in the tables of reflective self-analysis and cards of self-evaluation. It is important to support the sufficient degree of self-confidence of teachers, to promote reestimation of their own personal capacities. Three main constituents - I want (incentive), I can (predictive), and I must (axiological) - determine the degree of human self-confidence; therefore, thorough analysis of self-state (self-reflection) is required to a teacher to improve self-estimation and mobilization of personal subject resources. At the final stage, it is assumed that the teacher will actively analyze the efficiency of mastering and implementation of ALM into own professional activity, mentioning his actions on selection and use of ALM in journal of self-monitoring. An obligatory condition for this is the creation of educational environment, providing open context education, active communication of participants in education, opportunity to select parameters of education and self-determination [7-9]. The base for correct choice will be orientation at individual capabilities, determined personal properties, and, what is more important, at the level of formation of subject experience and the degree of evidence of its main components [10-12]. Implementation of ALM into activity of teacher of higher education should be considered, firstly, as expansion of subject space of personality and formation of acmeological invariants of professionalism by mastering modern technologies of solution to professional tasks aimed at improvement of own pedagogical activity [13-15]. The teachers of SAH, participating in the experiment with assistance by the heads of structural departments, actively used the developed model of pedagogical support. For half a year the teachers logged their monitoring and arranged flowcharts of self-training, filled in the cards of self-evaluation and tables of reflective selfanalysis. This documentation, reflecting the main stages of selection and mastering ALM, promoted analysis of efficiency of ALM implementation into own activity of teachers of higher education.

\section{Conclusion}

Upon retesting of main components of professional subject experience, it has been revealed that the number of academic staff with low level of professional subject experience decreased from 11 (26.1\% of all participants in the experiment) to $5(11.9 \%)$ persons. At the start of the research, the medium level of professional subject experience was detected for most of teachers: 28 persons $(66,6 \%)$; however, after the use of the developed model of pedagogical support, their number decreased to 16 persons (38.1\%). High level of professional subject experience, which before the experiment was observed only in three teachers $(7.1 \%)$, was detected already in a half of the teachers (21 persons - 50.0\%) after the experiment. Therefore, as a consequence of practical implementation of the developed model of pedagogical support in SAH, Far Eastern Federal University, it was possible to increase the number of teachers, ready to use ALM in own pedagogical activity, from $41.0 \%$ to $76.0 \%$, 
the remaining $24.0 \%$ of teachers agreed to master ALM, planning to start from the less complex and labor intensive. We believe that the positive dynamics of the level of formation of main components of teacher's professional subject experience, increased motivation to construct own methodological system of teaching academic disciplines using ALM, are the indicators of efficiency of the proposed model of pedagogical support consecutively implemented in four stages of humanitarian education in metropolis.

\section{References}

1. N.Ya. Bolshunova, Usloviya i sredstva razvitiya sub"yektnosti [Conditions and means for the development of subjectivity], Thesis (Novosibirsk State Pedagogical University, Novosibirsk, 2007)

2. V.V. Serikov, Obrazovaniye i lichnost'. Teoriya i praktika proyektirovaniya pedagogicheskikh sistem [Education and personality. Theory and practice of designing pedagogical systems] (Logos, Moscow, 1999)

3. V.A. Slastenin, N.G. Rudenko, Pedagogue, 3, 93 (1997)

4. Ye.V. Akulinina, Formirovaniye sub"yektnoy pozitsii lichnosti v protsesse postdiplomnogo obrazovaniya [Formation of the subjective position of the individual in the process of postgraduate education], Thesis (Starooskolsk Technological Institute (branch) of the State Technological University "Moscow Institute of Steel and Alloys", Moscow, 2008)

5. M.V. Yermolayeva, Subyektnyy podkhod v psikhologii razvitiya vzroslogo cheloveka (voprosy i otvety) [Subjective approach in developmental psychology of an adult (questions and answers)] (MODEK, Voronezh, 2006)

6. V.A. Petrovsky, Lichnost': fenomen subyektnosti [Personality: the phenomenon of subjectivity] (Phoenix, Rostov-on-Don, 1993)

7. K.A. Abulkhanova-Slavskaya, Mir psikhologii, 1(65), 22-31 (2011).

8. M.T. Gromova, Higher education in Russia, 4, 105-108 (1994)

9. A.K. Osnitsky, Voprosy psikhologii, 1, 5-19 (1996)

10. A.A. Badayev, Aktivnyye metody obucheniya [Active teaching methods] (Profizdat, Moscow, 1986)

11. Yu.L. Blinova, Subyektnaya pozitsiya pedagoga: teoriya i psikhologoakmeologicheskoye soprovozhdeniye [Subject position of the teacher: theory and psychological and acmeological support] (Tatar State University of Humanities and Education, Kazan, 2010)

12. Ye.Yu. Mandrikova, Psikhologicheskaya diagnostika, 2, 59-83 (2010)

13. Ye.N. Volkova, Subyektnost' pedagoga: Teoriya i praktika [The personality of a teacher: theory and practice], Thesis (Nizhny Novgorod Institute of Education Development, Moscow, 1998)

14. E. Deci, R. Ryan, The dynamics of self-determination in personality and development, in Self-related cognitions in anxiety and motivation (Lawrence Eribaum, Hillsdale, 1986)

15. R. Harre, Social being (Blackwell, Oxford, 1979) 